\title{
TRADUZIR: ESCREVER ENTRE LÍNGUAS
}

\author{
Luis S. Krausz ${ }^{1}$ \\ -Universidade de São Paulo, São Paulo, São Paulo, Brasil
}

\begin{abstract}
Resumo: Este artigo propõe-se a investigar em que medida as ideias metafísicas relacionadas à linguagem e aos poderes da linguagem, tanto na tradição grega arcaica de Homero e Hesíodo quanto na tradição bíblica do livro de Gênesis, que, durante o século $\mathrm{XX}$, foram novamente trazidas à tona, discutidas e reavaliadas por autores como Walter Benjamin e Bruno Schulz, também fazem sentido enquanto contribuições para uma discussão em torno da natureza da tradução literária. Estas ideias provenientes da Antiguidade estão vinculadas, por um lado, a uma visão da linguagem como uma dyamis original e autônoma, como uma força criadora de sentidos, que antecede a "realidade" para tornar-se o real em si mesmo, e se contrapõem aos conceitos linguísticos estabelecidos por Ferdinand de Saussure e Émile Benveniste, que partem de uma abordagem prática da linguagem e postulam o caráter arbitrário dos vocábulos. Na concepção essencialista da linguagem, própria do mundo arcaico, assim como no conceito goethiano de Verwandtschaft (afinidade) talvez se encontrem contribuições valiosas para a práxis da tradução literária.
\end{abstract}

Palavras-Chave: Tradução; Poética; Afinidade; Interlíngua; Terminologia

\section{TRANSLATING: WRITING BETWEEN LANGUAGES}

\begin{abstract}
This article investigates to what extent the metaphysical ideas concerning language and its powers, present in the archaic Greek tradition of Homer and Hesiod as well as in the biblical book of Genesis, and discussed and reevaluated by authors such as Walter Benjamin and Bruno Schulz in the 20th. Century, can contribute for the discussion about the nature of literary translation. These ideas, whose origin is in Antiquity, are associated, on the one hand, to a vision of language as an original and autonomous dynamis, as a sense=generating power which precedes
\end{abstract}


reality to become the real itself, and are thus diametrically opposed to the linguistic concepts established by Ferdinand de Saussure and Émile Benveniste, which are based on a practical approach to language, and which take the arbitrary character of words for granted. In the essentialist concept of language, typical of the archaic world, as well as in Goethe's idea of Verwandtschaft (affinity) some valuable contributions for the praxis of literary translation might be found.

Keywords: Translation; Poetics; Affinity; Intermediate Language; Terminology

As palavras, em português, são também chamadas de "termos", do latim "terminus", ou seja, término, fim, limite. Segundo o dicionário Aurélio Buarque de Holanda, "termo" é um "vocábulo ou locução que denomina conceito prévia e rigorosamente definido, peculiar a uma ciência, arte, profissão, ofício." Ora "termo", no seu sentido original de "término", como no francês "terminus", que designa o ponto final de uma ferrovia, por exemplo, remete, necessariamente, à ideia de percurso, de trajeto: as palavras, em suas formas correntes são de fato os pontos finais provisórios de longos percursos. E a tradução consiste, igualmente, num percurso, que tem sua origem em determinado idioma e seu destino em outro.

A origem destes percursos está no passado remoto, em línguas já esquecidas ou abandonadas, mas cujas potências originais impregnam os sentidos dos termos atuais como uma espécie de atavismo, como uma carga genética oculta. A etimologia nada mais é do que a tentativa de percorrer, na contramão, estes trajetos, isto é, uma espécie de arqueologia dos sentidos, enquanto as formas atuais das palavras, evidentemente, são tão provisórias quanto qualquer uma das estações anteriores nos percursos por elas descritos, cuja origem está num passado insondável, e cujo destino, no futuro, é tão incerto quanto cada uma das estações pelas quais passaram seus caminhos.

Ao contrário do ponto final de uma ferrovia, do "terminus", portanto, as palavras nada mais são do que paradas provisórias num trajeto cuja origem se perde de vista, e cujo destino se perde, igualmente, no horizonte do futuro. Para cada geração, porém, estas estações provisórias ganham o estatuto ilusório de pontos finais, de 
conceitos aos quais podemos nos agarrar, Begriffe, como se diz em alemão - um substantivo que está ligado ao termo greifen, agarrar.

Os conceitos conhecidos proporcionam-nos segurança e estabilidade, são como tábuas de salvação no oceano dos sentidos em permanente movimento e transformação, são rochas firmes - ou aparentemente firmes - na superfície sempre mutável da consciência, que nos proporcionam uma ilusória sensação de permanência em meio a um universo de inconstância e de dúvidas.

Com as palavras, com os termos, construímos muralhas: nossas cidadelas do sentido, que opõem uma resistência provisória à mutabilidade. Essas, como as que cercavam as cidades medievais, estão condenadas à ruína e ao desaparecimento, mas, mesmo assim, nos oferecem segurança, nos sobrevivem e deixam, no tempo, seus rastros e suas marcas.

Assim, as palavras, em suas conformações transitórias, são vias, pelas quais trafega o sentido. Mas podemos supor que todas partiram de um mesmo ponto, ainda que se dirijam, por rotas divergentes, a lugares cada vez mais afastados um do outro.

Este ponto de origem comum estaria, segundo o livro de Gênesis, na linguagem por meio da qual Deus criou o Universo, que é também aquela por meio da qual Adão, no sexto dia da Criação, deu nome a tudo o quanto existe. Pois, conforme se lê em Gênesis I, tudo o quanto existe foi criado por meio de palavras. Walter Benjamin ("Über Sprache überhaupt und über die Sprache des Menschen”: 140-157) (refere-se a esta língua original, pré-babélica, numa teoria da linguagem que é claramente influenciada pelo messianismo judaico. Ele não parte da suposição tradicional dos estudos linguísticos, que postula ser a língua um meio de comunicação criado arbitrariamente e convencionado pelo homem, mas parte da suposição mítica de que haveria uma língua original, uma vertente da qual surgiram os rios das muitas línguas. Assim, ele defende a ideia de uma língua primeva, a língua adâmica, na qual não haveria contraposição entre forma e conteúdo, mas sim uma valorização do nome, do qual emanaria uma energia mágica e criadora. 
O ser espiritual de alguma coisa, portanto, não consiste, para Benjamin, de uma representação na linguagem, mas é algo que antecede esta representação. O Ser espiritual do homem é, para Benjamin, a língua e, portanto, a ligação entre as palavras e as coisas não pode, como supõe a linguística moderna, de Ferdinand de Saussure e de Émile Benveniste, ser fortuita nem arbitrária. Segundo esta teoria da linguagem, a palavra é o próprio ser da coisa, é a sua essência - e não um signo arbitrário, um nome que lhe foi atribuído a posteriori.

Diante deste pressuposto, Benjamin considera necessário examinar o conceito de tradução a partir das camadas mais profundas da teoria da língua. Pois, para ele, as línguas podem ser consideradas como diferentes traduções e derivações de termos originais e criadores, ou seja, aqueles da Ursprache, a língua original, cujos ecos estariam presentes em todas as línguas, e assim lhes permitiriam partilhar do caráter mágico desta língua original. As palavras, em diferentes idiomas, seriam, portanto, diferentes estações em percursos que partiram de um mesmo ponto e seriam, assim, inevitavelmente aparentadas umas das outras.

Em Die Aufgabe des Übersetzers (A tarefa do tradutor), Walter Benjamin afirma que é prejudicial e mesmo impossível levar em consideração um leitor ou um receptor no momento da criação de uma obra de arte, e com isto reafirma o caráter absoluto da linguagem. A postura estética de Benjamin coincide com noções relativas à linguagem, e em particular à linguagem poética, que são próprias da antiguidade clássica, e atribuem à arte de um modo geral e à criação poética em particular uma origem sobre-humana, percebendo-as como manifestações numinosas, não condicionadas pelas contingências humanas, que pressupõem a autonomia e a inexorabilidade do ímpeto artístico e, consequentemente, um domínio do mesmo sobre todas as formas e regras da sociabilidade humana.

Bruno Schulz, no denso e sucinto ensaio "A mitificação da realidade", enuncia uma teoria da linguagem que, assim como a de Benjamin, é também marcada pelas ideias tradicionais judaicas que dizem respeito à "língua criadora" tanto quanto pelas ideias de lin- 
guagem poética próprias da Grécia arcaica. Para Schulz, todas as palavras remeteriam a uma origem de caráter mítico, e cada palavra seria um fragmento atenuado de um vocábulo eterno, imantado com uma dynamis, com uma força cujos resquícios estariam ocultos - e frequentemente esquecidos - no interior das palavras, em suas formas atuais. Ou seja, as palavras, tais quais as conhecemos, seriam derivações distantes das "palavras primordiais", daquelas que eram capazes de constelar, à sua volta, sentidos, ordens e realidades inteiras.

\section{A palavra criadora}

Aproximar-se desta origem, partindo da palavra em uma língua para buscar a palavra correspondente em outra língua seria, de acordo com esta visão, a missão do bom tradutor: aquele que tem os olhos, os ouvidos e o coração abertos para a alma original que habita o interior de cada palavra.

Em seu ensaio, Schulz compreende a palavra como fragmento de uma realidade metafísica, de uma mitologia original. Pois, para ele, cada palavra é por si só o fragmento de uma mitologia. E o papel do poeta, segundo Schulz, não é outro senão o de um restaurador, o de alguém que se dedica a restituir, a cada uma das palavras que passa por suas mãos, estes significados e dinamismos que se perderam por meio do uso profano, por meio daquilo que Schulz denominou de seu uso "técnico", que seria o de servir de instrumento para a representação das realidades tardias, construídas pelo homem da era da ciência, da razão e da indústria. As palavras atenuadas, as das línguas "práticas", que, não obstante suas limitações, possuem pretensões absolutas, acabaram obliterando aquela outra realidade, metafísica, transcendental, à qual pertenciam os vocábulos originais das quais elas são derivadas.

Para Schulz, vivemos numa época de inversão de valores. Nossas concepções cientificistas e racionalistas nos levam a acreditar que as palavras seriam representações ou imagens da realidade. 
Mas na verdade, segundo Schulz (241), o que acontece é exatamente o inverso: a realidade é que seria uma sombra da palavra. Schulz afirma que "cada fragmento da realidade só existe graças à circunstância de possuir uma parte do sentido universal." Ainda segundo Schulz, "as antigas cosmogonias expressam este fato por meio da frase de que no princípio estava o verbo." (Schulz, 241)

Para Schulz, ocupar-se com literatura, com poesia, é também percorrer em sentido inverso este caminho de afastamento das palavras em relação à sua origem, é retornar aos seus sentidos originais, é conhecer um pouco daqueles poderes criadores que lhe foram inerentes um dia. "As palavras em suas formas atuais", diz Schulz, "são apenas fragmentos, remanescentes de uma mitologia original, que abarcava a tudo. Por isto as palavras tendem, naturalmente, a crescer, a se regenerar, para recuperar a plenitude de seu sentido." (Schulz, 241)

O papel do poeta, do escritor, é, para Schulz, operar esta transmutação, é reconduzir cada palavra de volta à sua fonte. Schulz compara o poder das palavras aos de uma serpente lendária que foi esquartejada, mas cujas partes buscam, umas pelas outras, no escuro, para reconstruir o animal original que constituíram um dia. O organismo integral das palavras foi despedaçado em milhões de expressões individuais, em sons, em idiomas e, desta forma, foi submetido aos interesses e às necessidades da vida prática. A palavra foi subjugada aos condicionamentos e às leis da técnica. E o papel do poeta é libertá-la desta prisão, recompor as antigas ligações, reconduzir cada palavra de volta para mais perto do seu lugar inicial.

A saudade da palavra, a ânsia da palavra pelo retorno a este seu lar é o que chamamos de poesia. Segundo Schulz, "a poesia consiste de curtos-circuitos do sentido em meio às palavras, consiste de regenerações dos mitos originais." (Schulz, 241) As palavras são por ele comparadas aos escombros e aos fragmentos de antigos templos em ruínas, com os quais o homem moderno, como um bárbaro, constrói suas casas. Cada uma destas palavras provém do grande templo da mitologia, e o dever do poeta, ao juntar as palavras, é reconstruir o que for possível do templo que era o seu lar original. 


\section{O limbo da interlíngua}

Ao se debruçar sobre a tarefa da tradução literária, portanto, o tradutor não deveria perder de vista o fato, destacado por Benjamin tanto quanto por Schulz, de que as palavras, em seu estado atual, são derivações distantes, são os reflexos e os cacos de uma origem remota, velada aos nossos olhos pela escuridão dos séculos, no Hades por onde circulam as palavras esquecidas, na necrópole das línguas extintas, que é também o húmus do qual brotam as novas palavras.

De fato, a tarefa (em alemão, Aufgabe) do tradutor parece envolta por uma dupla roupagem, que implica, de um lado, num compromisso do tradutor com o texto e com a linguagem de origem da obra a ser traduzida, mas, ao mesmo tempo, numa renúncia (pois o verbo alemão aufgeben significa, também, renunciar) do tradutor à própria voz e à autonomia da sua própria língua, e uma submissão, não sem um certo grau de violência, à língua original do texto a ser traduzido.

Esta complexa relação entre língua de origem e língua de destino seria governada, segundo as ideias de Benjamin investigadas no ensaio Die Aufgabe des Übersetzers, pelo princípio da semelhança ou, em alemão, Verwandtschaft - outro dos termos cruciais no pensamento benjaminiano, igualmente marcado pela duplicidade de sentidos. Pois Verwandtschaft significa afinidade (como nas Afinidades eletivas de Goethe), ou seja, uma proximidade de caráter mágico-magnético, que foge às explicações racionais e depende de uma constelação de motivos emocionais (e emocionantes) e significa, ao mesmo tempo, parentesco, ou seja, algo que é imposto pela genealogia, à revelia da vontade ou de qualquer movimento da subjetividade individual.

O princípio da Verwandtschaft, assim, posto como o fundamento da tradução, também parece subsistir e exercer seus efeitos de maneira ambígua, em meio à tensão subjacente a seus dois significados que são, em certa medida, opostos: o que se refere ao caráter eletivo, que supõe uma espécie de atração erótica entre vocábulos de idiomas diversos, e aquele associado à inexorabilidade da 
genética e da descendência, isto é, um parentesco determinado por aquelas leis e códigos que regem as equivalências entre as línguas.

Entre a obrigatoriedade dos sistemas léxicos, codificados pelos dicionários e pelas etimologias, e a liberdade na relação de livres afinidades entre palavras de línguas diferentes, cuja vida própria e independente também tende em determinadas direções e caminha rumo a determinados sentidos, levada, justamente, por determinadas forças que parecem "naturais" - e que são, portanto, independentes dos códigos e das convenções - cabe ao tradutor fazer os "casamentos" cabíveis entre o idioma de origem e o de destino.

Assim, se ao traduzir, o tradutor estaria renunciando, simultaneamente, a duas coisas: sua voz e seu idioma, e submetendo-se, como um criado - ou um escravo - à língua e à voz de um outro - estaria, ao mesmo tempo, libertando as palavras de seus lugares estabelecidos nos léxicos e nos códigos, e concedendo-lhes a possibilidade de irem buscar, em outro idioma, novas dimensões dos seus sentidos.

É sobre este espaço caótico e superpovoado, que separa as línguas em sua forma atual da língua adâmica tanto quanto das línguas que ainda estão por vir, que gostaria de me ater por um momento. Pois é na escuridão e no silêncio sepulcral deste lugar que o tradutor se vê condenado a perambular quando, em seu ofício, abandona uma língua para partir em busca de suas correspondências e de suas afinidades em outra língua.

Este lugar é o lugar da interlíngua, das relações ilícitas entre palavras de línguas diferentes, um lugar assustador, de insegurança e de incerteza, de trevas e de vertigem, um mundo das antípodas, cujas fronteiras são delimitadas, por um lado, pelos limites das línguas estabelecidas e, por outro, pelo ponto original de onde partiram todas as línguas.

Frequentar este lugar, ou melhor, este não-lugar, é uma tarefa ousada. Ir para lá significa retirar-se, por um momento, da segurança e das certezas que imperam no mundo luminoso e bem organizado das línguas sistematizadas para ingressar num âmbito caótico, num Hades das palavras que, em certa medida, como aquele que 
Ulisses visita no "Canto X" da Odisseia. Pois as sombras que pairam por este reino subterrâneo não têm mais voz e só são capazes de falar na medida em que o herói grego lhes permite beberem o sangue dos animais que foram sacrificados antes de sua descida aos ínferos. De sua visita ao Hades das palavras, talvez depois de oferecer aos fantasmas que pairam no submundo da interlíngua um pouco do próprio sangue, o tradutor volta com uma mercadoria furtada ou contrabandeada: a palavra que será levada, imediatamente, para o mundo bem organizado da língua de destino, que o aguarda, como um lugar de calor e luz, como um "terminus" - ainda que ilusório do outro lado do reino das trevas que ele acaba de cruzar.

Assim, cabe ao tradutor circular por este lugar assombrado, que se quer transpassar com rapidez, como o clarão de um raio. Sua única arma ao percorrer este limbo sinistro e escabroso é aquilo que Ciryl Aslanov (2015: 32) denomina Sprachgefühl, ou seja, sentimento (ou sensação) da língua - algo tão imprescindível para o trabalho de tradução quanto indefinível em termos mais concretos.

Trata-se, de fato, de uma espécie bússola ou de sexto-sentido, de um guia hermético, capaz de transformar essa incursão à terra de ninguém, que se estende no vácuo entre as línguas, em algo menos assustador, e por vezes até mesmo num passeio agradável e inspirador.

Penso que as indicações deste guia, que iluminará o mundo de trevas, se encontram inscritas no original a ser traduzido. $\mathrm{O}$ tradutor, por isso, precisa, antes de qualquer outra coisa, ser um bom leitor. Pois é a partir da leitura que ele adquirirá as senhas que o conduzirão em sua incursão às trevas da interlíngua. E ler exige, muitas vezes, mais esforço e mais cuidado do que escrever. Pois as verdades literárias estão por trás - e por dentro - das formas das palavras.

Traduzir cada palavra e cada frase é como subir uma montanha deste mundo imaginário, contemplar o que se avista dali para então descê-la por outro caminho. A subida corresponde à leitura, que quer conduzir a algum lugar muito particular, além das línguas. A descida deve trazer consigo as lembranças e as imagens das paisagens que se acabam de visitar, deste lugar que está antes e além 
das palavras, e cujos contornos só podem ser sugeridos por meio destas. Pois, ainda segundo Bruno Schulz (241), "a linguagem é o órgão metafísico do ser humano".

Assim, o inferno e a cegueira da interlíngua transformam-se, por um instante, num vislumbre do paraíso perdido da língua pré-babélica. O tradutor, assim como o escritor, precisa ser um caminhante. Se o escritor segue suas próprias trilhas, desbrava lugares nunca antes visitados, revela penhascos, desertos e florestas, o tradutor é seu hóspede, seu convidado e companheiro de jornada, alguém que observa e reflete e depois leva suas impressões, lembranças e sentimentos em seu caminho de volta à própria casa, que é sua outra língua. Traduzir é bem mais, portanto, como escrever sobre memórias e impressões de visitas e de viagens que fizemos a outros lugares.

A fidelidade que o tradutor deve ao original não se prende às palavras tomadas isoladamente, em seu sentido corriqueiro e prático, mas justamente àquilo que, por meio delas, o autor não foi capaz de dizer, e sim de constelar.

O impulso poético, na Grécia antiga, era atribuído a divindades, as Musas, e a poesia tinha, neste mundo arcaico, um valor sagrado. Quando os poetas da antiga Grécia tentam descrever os efeitos da poesia, recorrem, sempre, à linguagem da magia e do encantamento. "Homero refere-se, repetidas vezes, à canção dos poetas como Thelxis, um poder encantatório capaz de enfeitiçar o ouvinte até mesmo contra sua vontade consciente." (Segal, 1989: 14)

O poder compulsório e irresistível da linguagem, o seu magnetismo, capaz de constelar realidades próprias, é uma força que pode ser percebida como mágica, mas também perigosa. E entregar-se a esse fluxo espontâneo e misterioso da linguagem significa deixar-se levar a um lugar que está além da própria linguagem.

Benjamin reafirma, assim como o livro de Gênesis e os mitos gregos, o caráter absoluto que paira em torno da linguagem para, em seguida, lançar uma pergunta: o que se passa com a tradução? Ela é concebida apenas como uma ponte para amparar aqueles que não têm a capacidade de compreender o original? Ou partilha, com 
a literatura e com a poesia, do mistério da linguagem, de sua autonomia e de sua resistência aos condicionamentos, de seu caráter autônomo e espontâneo, misterioso e mágico?

Será a tradução, então, uma arte de segunda categoria, que se vê obrigada a repetir, em outro idioma, aquilo que já foi dito pelo original? Mas, afinal, o que "dizem" uma poesia ou uma obra literária? Segundo Benjamin, dizem muito pouco àqueles que a "compreendem". Isto porque o conteúdo da poesia, o conteúdo de qualquer obra literária, não está naquilo que ela comunica e pronuncia, mas sim naquelas presenças que é capaz de constelar, ou seja, naquilo que não diz.

Traduzir é interpretar, é redescobrir e renovar o universo do texto poético e é também complementá-lo com novas percepções. Pois, se o texto poético, em sua língua de origem, é apenas uma das versões de si mesmo, suas traduções são suas outras possibilidades.

A interlíngua, portanto, pode tornar-se, também, o lugar paradisíaco de onde jorra a fonte do texto, o lugar onde se podem encontrar uma nova forma deste mesmo texto, ou seja, sua expressão em outra língua.

\section{Referências}

Aslanov Ciryl. A tradução como manipulação. São Paulo: Perspectiva, 2015.

Benjamin, Walter. "Die Aufgabe des Übersetzers". Iluminationen. Frankfurt a. M.: Suhrkamp, 1977.

Benjamin, Walter. "Über Sprache überhaupt und über die Sprache des Menschen”, Gesammelte Schriften, vol. II-1, Frankfurt a.M.: Suhrkamp, 1991, pp. 140-157. 
Ferreira, Aurélio Buarque de Holanda. Novo Aurélio - O dicionário da Língua Portuguesa. Rio de Janeiro: Editora Nova Fronteira, 1999.

Goethe, Johann Wolfgang von. Die Wahlverwandtschaften em Goethes Werke, vol 8., Leipzig: Bibliographisches Institut, 1916.

Krausz, Luis S. As Musas: poesia e divindade na Grécia Arcaica. São Paulo: EDUSP, 2006.

Segal, Charles. Orpheus, the myth of the poet. Baltimore, Johns Hopkins University Press, 1989

Schulz, Bruno. "Das Mythisieren der Wirklichkeit". Die Wirklichkeit ist Schatten des Wortes, Ficowski, Jerszy (Ed.). München: Deutsches Taschenbuchverlag, 2000.

The Holy Scriptures. Philadelphia: Jewish Publication Society of America, 1982.

Recebido em: 09/05/2021

Aceito em: 10/08/2021

Publicado em setembro de 2021

Luis S. Krausz. Email: krausz@usp.br. ORCID: https://orcid.org/0000-00021753-9470. 